Address correspondence to: Rona G. Giffard, Stanford University School of Medicine, 300 Pasteur Drive, Grant Building S272A, Stanford, California 94305-5117, USA. Phone: 650.725.8482; Fax: 650.725.8052; E-mail: rona.giffard@stanford.edu.

1. Georgopoulos C, Welch WJ. Role of the major heat shock proteins as molecular chaperones. Ann Rev Cell Biol. 1993;9:601-634.

2. Lindquist S, Craig EA. The heat-shock proteins. Ann Rev Genet. 1988;22:631-677.

3. Mayer MP, Bukau B. Hsp70 chaperones: cellular functions and molecular mechanism. Cell Mol Life Sci. 2005;62(6):670-684.

4. Young JC, Agashe VR, Siegers K, Hartl FU. Pathways of chaperone-mediated protein folding in the cytosol. Nat Rev Mol Cell Biol. 2004;5(10):781-791.

5. Fleshner M, Johnson JD. Endogenous extra-cellular heat shock protein 72 : releasing signal(s) and function. Int J Hypertherm. 2005;21(5):457-471.

6. Mambula SS, Calderwood SK. Heat shock protein 70 is secreted from tumor cells by a nonclassical pathway involving lysosomal endosomes. J Immunol. 2006;177(11):7849-7857.

7. Brocchieri L, Conway de Macario E, Macario AJL. hsp70 genes in the human genome: conservation and differentiation patterns predict a wide array of overlapping and specialized functions. BMC Evol Biol. 2008;8:19.

8. Asea A, et al. Novel signal transduction pathway utilized by extracellular HSP70: role of toll-like receptor (TLR) 2 and TLR4.J Biol Chem. 2002;277(17):15028-15034.

9. Senf SM, Howard TM, Ahn B, Ferreira LF, Judge AR. Loss of the inducible hsp70 delays the inflammatory response to skeletal muscle injury and severely impairs muscle regeneration. PLoS One. 2013;8(4):e62687.

10. May LA, et al. Inner ear supporting cells protect hair cells by secreting HSP70. J Clin Invest. 2013;123(8):3577-3587.

11. Macario AJL, Conway de Macario E. Sick chaperones, cellular stress, and disease. $N$ Engl J Med. 2005;353(14):1489-1501.

12. Andersson U, Tracey KJ. Neural reflexes in inflammation and immunity. $J$ Exp Med. 2012;209(6):1057-1068

13. Tytell M. Release of heat shock proteins (Hsps) and the effects of extracellular Hsps on neural cells and tissues. Int J Hypertherm. 2005;21(5):445-455.

14. Tonkiss J, Calderwood SK. Regulation of heat shock gene transcription in neuronal cells. Int J Hypertherm. 2005;21(5):433-444.

15. Guzhova I, et al. In vitro studies show that Hsp70 can be released by glia and that exogenous Hsp70 can enhance neuronal stress tolerance. Brain Res. 2001;914(1-2):66-73

16. Brown IR. Heat shock proteins and protection of the nervous system. Ann N Y Acad Sci. 2007;1113:147-158

17. Giffard RG, Han R-Q, Emery JF, Duan M, Pittet JF. Regulation of apoptotic and inflammatory cell signaling in cerebral ischemia: the complex roles of heat shock protein 70 . Anesthesiology. 2008;109(2):339-348.

18. Prahlad V, Morimoto RI. Integrating the stress response: lessons for neurodegenerative diseases from C. elegans. Trends Cell Biol. 2009;19(2):52-61.

19. Pockley AG, Calderwood S, Multhoff G. The atheroprotective properties of Hsp70: a role for Hsp70-endothelial interactions? Cell Stress Chap. 2009;14(6):545-553.

20. Van Eden W, Wick G, Albani S, Cohen I. Stress, heat shock proteins, and autoimmunity. Ann NY Acad Sci. 2007;1113:217-237.

21. Thériault JR, Mambula SS, Sawamura T, Stevenson MA, Calderwood SK. Extracellular HSP70 binding to surface receptors present on antigen presenting cells and endothelial/epithelial cells. FEBS Lett. 2005;579(9):1951-1960.

22. Basu S, Binder RJ, Ramalingam T, Srivastava PK. CD91 is a common receptor for heat shock proteins gp96, hsp90, hsp70, and calreticulin. Immunity. 2001;14(3):303-313.

\title{
Chronic THC intake modifies fundamental cerebellar functions
}

\author{
Nephi Stella \\ Department of Pharmacology, University of Washington, Seattle, Washington, USA.
}

\begin{abstract}
Delta9-tetrahydrocannabinol (THC), the principal bioactive component in the Cannabis plant, is truly a captivating drug. Acute and chronic THC intake produces a spectrum of biological effects ranging from transient psychotropic effects to prolonged medicinal benefits, many of which have been fostered for centuries by our society. In the July 2013 issue of the JCI, Cutando et al. combined mouse genetics with classic mouse behavioral analysis to deepen our understanding of the physiological consequence of subchronic THC intake on eyeblink reflexes, a fundamental neuronal adaptive response, revealing that this regimen leads to downregulation of the cannabinoid $\mathrm{CB}_{1}$ receptor (referred to as $\mathrm{CB} 1$ in the Cutando et al. article) in cerebellar stress fibers and the activation of microglia, raising provocative new questions about the safety profile of regimented THC intake.
\end{abstract}

\section{Consequences in the blink of an eye}

Our detailed understanding of the molecular mechanism of action of THC on neuronal activity began 20 years ago with the molecular identification of the gene encoding for $\mathrm{CB}_{1}$ receptors, which mediate the psychoactive effects produced by

Conflict of interest: The author has declared that no conflict of interest exists.

Citation for this article: J Clin Invest. 2013; 123(8):3208-3210. doi:10.1172/JCI70226. this compound (1). $\mathrm{CB}_{1}$ receptors represent one of the most abundant $G$ proteincoupled receptors expressed in the brain, although the expression level and coupling mechanism vary according to neuron type (2). Activation of $\mathrm{CB}_{1}$ receptors by endogenous cannabinoid ligands, the endocannabinoids (eCBs), modulates neuronal activity at 4 overarching levels: by guiding neuronal patterning and connectivity during brain development (3); by modulating neurotransmitter release probability (4); by mediating short-term and long-term synaptic plasticity and shaping neuronal network connectivity $(5,6)$; and by controlling the expression of prosurvival proteins that promote neuronal endurance in response to brain injuries and pathologies (7). Unlike eCBs, THC activates $\mathrm{CB}_{1}$ receptors with its own pharmacodynamic profile and thus may impinge upon neuronal activity at these 4 levels (8).

The effect of THC on higher sensory, intentional, and memory processes has been intensely studied, but more recently, a major research focus has been on how THC affects neuronal activity at the systems level, revealing the breadth of THC's impact on behavior. In the current study, Cutando et al. (9) investigated the effect of subchronic THC exposure on cerebellar function. The cerebellum represents a key relay structure involved in the fine tuning of motor coordination, the implementation of associative learning, and the processing of temporal operations. Cutando et al. (9) found that subchronic THC exposure led to the impair- 


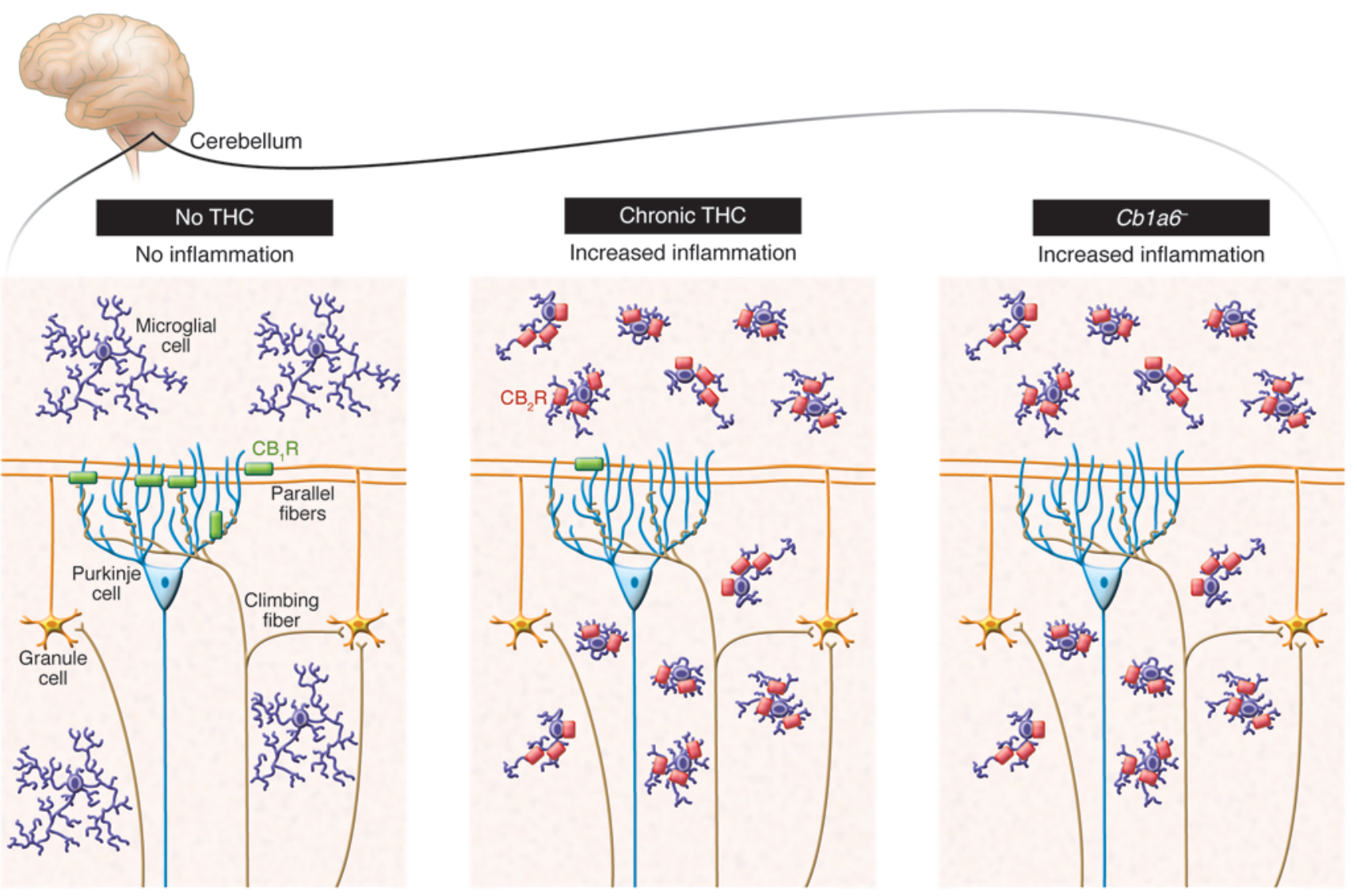

Figure 1

In mice, subchronic treatment with $\mathrm{THC}$ leads to the downregulation of presynaptic cannabinoid $\mathrm{CB}_{1}$ receptors expressed by parallel fibers that project onto Purkinje cells. Cutando et al. (9) show that the loss of $\mathrm{CB}_{1}$ receptors, either due to TCH-induced downregulation or genetic deletion, triggers a neuroinflammatory response typified by changes in microglial cell morphology and $\mathrm{CB}_{2}$ receptor expression. This adaptive response underlies THC-induced deficits in cerebellar-associated learning functions.

ment of motor coordination and eyeblink reflex conditioning in mice, both of which are archetypal examples of cerebellar-associated learning. Eyeblink conditioning was achieved by presenting an auditory stimulus (i.e., conditioned stimulus [CS]) to the mice, followed by an eyeblink-eliciting unconditioned stimulus (US) elicited by a mild air puff. Following repeated CS-US trials, a conditioned response $(\mathrm{CR})$ that preceded US onset was measured. In humans, repeated THC intake has previously been shown to markedly reduce the incidence and timing of this neuronal adaptive response (10). Here, Cutando et al. (9) found in mice that the THC-induced behavioral impairment was related to the rapid and strong downregulation of $\mathrm{CB}_{1}$ receptors.

How lighting up ignites inflammation What would be the significance of losing eCB signaling through $\mathrm{CB}_{1}$ receptors, and what brain areas would be affected by this change? Loss of presynaptic $\mathrm{CB}_{1}$ receptor signaling and control of neurotransmitter release increases the probability of glutamate release and promotes excitotoxicity $(7,11)$. Microglial cells, the macrophages of the brain, act as sentinels for neuronal dysfunction and injury, constantly surveying the parenchyma by extending and retracting their fine processes and sampling for the presence of cell damage signals and pathogens (12). Once microglia encounter such a signal of injury or pathogen, they undergo a rapid change in phenotype that empowers them with immune functions tailored to attempt to reduce and repair any tissue damage. Accordingly, one can monitor brain tissue for microglial cell activation and easily locate the damaged areas. In this study, the authors found that subchronic THC intake leads to microglial activation specifically in the cerebellum. To further define the cellular components mediating this neuroinflam- matory response, Cutando et al. developed a new mouse model that lacks the $\mathrm{CB}_{1}$ receptor selectively in cerebellar parallel fibers (Cb1a6 mice) and found selective activation of microglia in the cerebellum of these mice, demonstrating that loss of $\mathrm{CB}_{1}$ signaling due to receptor downregulation or genetic deletion induces a neuroinflammatory response (ref. 9 and Figure 1). This seemingly simple result points to an important new concept: it suggests that one function of $\mathrm{CB}_{1}$ receptors expressed by cerebellar stress fibers is to maintain homeostasis within the cerebellum and that disruption of this homoeostasis triggers microglial cell activation and neuroinflammation. Remarkably, the authors found no direct evidence of neuronal damage, suggesting that the impaired neuronal adaptation measured by the eyeblink reflex was not due to actual neuronal loss but rather to changes in neurotransmitter release from the stress fibers onto Purkinje cells. 


\section{Connecting impaired $\mathrm{CB}_{1}$ signaling to neuroinflammation}

While $\mathrm{CB}_{1}$ receptor downregulation in response to repeated THC intake typically develops within hours, the ensuing neuroinflammatory response developed after 5 days in this experimental paradigm (9). To understand this delay, one needs to consider that alteration of the microglial phenotype is dynamic and complex and involves sequential changes in the expression of specific proteins, many of which have established roles in immune response. To start, while changes in microglial morphology unmistakably indicate cell activation, the actual differences in microglial cell morphologies (e.g., bushy versus amoeboid morphologies) remain difficult to interpret, as these do not necessarily correlate with particular immune phenotypes adopted by these cells. Conversely, quantifying changes in the expression of select proteins that have known biological roles in microglia may provide a sharper image of the microglial cell phenotype and the type of neuroinflammatory response that has developed in the parenchyma. In this study, the authors demonstrate an increased expression of 2 proteins with established immune functions in microglia: the cannabinoid $\mathrm{CB}_{2}$ receptor (referred to as CB2 in the Cutando et al. article) and the immune modulator IL-1 $\beta$ (9). Upregulation of $\mathrm{CB}_{2}$ receptors in microglia may indicate that these cells are now able to sense increases in local eCB levels resulting from neuronal overactivation and damage (13); activation of $\mathrm{CB}_{2}$ receptors in microglia directs their migration toward damaged cells and reduces their ability to release proinflammatory mediators, while promoting the release of repair mediators. Conversely, upregulation of IL- $1 \beta$ in microglia is typically associated with a proinflammatory phenotype and the propagation of the neuroinflammatory response (14). Thus, subchronic THC intake leads to the retraction of cell processes by microglia in order to adopt a bush morphology and leads to a concomitant upregulation of the proinflammatory cytokine IL- $1 \beta$ and antiinflammatory $\mathrm{CB}_{2}$ receptors. While further studies are required to better understand how this particular neuroinflammatory profile leads to behavior impairment, the authors show that blocking IL-1 signaling ameliorates THC-mediated impairment of the eyeblink reflex (9).

\section{High times for THC}

The study by Cutando et al. (9) in the July 2013 issue of the JCI outlines the molecular and cellular consequences of subchronic THC intake in a fundamental neuronal adaptive response involving the cerebellum. While our society is progressively accepting the legalization and commercialization of products containing THC for recreational and medicinal use, a portion of the population remains concerned about the health consequences associated with chronic or subchronic THC exposure. To reassure them, one might point to both the low incidence of side effects measured under strict clinical trial conditions when testing the therapeutic value of THC (15). However, the cerebellum is involved in fine tuning motor coordination, implementing associative learning, and processing temporal operations, and such behaviors are typically not measured under clinical trial settings and are rarely commented on by THC users. The study by Cutando et al. (9) raises fascinating new questions about the effect of subchronic THC intake on the cerebellum's ability to fine tune higher cognitive functions, including its ability to produce rhythmic neuronal activity, thought to be linked to the ability to estimate time. Studies pioneered by Valentino Braitenberg have suggested that the anatomical organization of Purkinje neurons and their precise and regular innervation and excitation by stress fiber synapses originating from granule cells are likely to encode precisely timed behaviors (16). Altered time perception is often reported by individuals with THC intoxication and could be linked to temporal disintegration that is linked to an increase in internal clock speed $(17,18)$. We now have the genetic and pharmacological tools to explore one of the most fascinating and mysterious biological questions, and one that is largely unanswered: how do we perceive time and how is this modified by drug intake?

These are exciting times for cannabinoid research. By combining mouse genetics and classic mouse behavioral analysis, Cutando et al. (9) have helped to map the neuronal types and pathways controlled by $\mathrm{CB}_{1}$ receptors, shedding light on THC's bioactivity on many fundamental biological functions and discovering how it regulates specific pathophysiological processes.

\section{Acknowledgments}

N. Stella receives support from NIH grants (DA014486 and DA026430).

Address correspondence to: Nephi Stella, Department of Pharmacology, joint with Psychiatry and Behavioral Sciences, 1959 N.E. Pacific St., BB-1538, HSC, Box 357280, Seattle, Washington 981957280, USA. Phone: 206.221.5220; E-mail: nstella@uw.edu.

1. Matsuda LA, Lolait SJ, Brownstein MJ, Young AC, Bonner TI. Structure of a cannabinoid receptor and functional expression of the cloned cDNA. Nature. 1990;346(6284):561-564.

2. Steindel F, et al. Neuron-type specific cannabinoidmediated $G$ protein signalling in mouse hippocampus. J Neurochem. 2013;124(6):795-807.

3. Berghuis P, et al. Hardwiring the brain: endocannabinoids shape neuronal connectivity. Science. 2007;316(5828):1212-1216.

4. Katona I, Freund TF. Endocannabinoid signaling as a synaptic circuit breaker in neurological disease. Nat Med. 2008;14(9):923-930.

5. Kreitzer AC, Malenka RC. Endocannabinoidmediated rescue of striatal LTD and motor deficits in Parkinson's disease models. Nature. 2007;445(7128):643-647.

6. Robbe D, Montgomery SM, Thome A, RuedaOrozco PE, McNaughton BL, Buzsaki G. Cannabinoids reveal importance of spike timing coordination in hippocampal function. Nat Neurosci. 2006;9(12):1526-1533.

7. Marsicano G, et al. CB1 cannabinoid receptors and on-demand defense against excitotoxicity. Science. 2003;302(5642):84-88.

8. Straiker A, Mackie K. Cannabinoids, electrophysiology, and retrograde messengers: challenges for the next 5 years. AAPS J. 2006;8(2):E272-E276.

9. Cutando L, et al. Microglial activation underlies cerebellar deficits produced by repeated cannabis exposure. J Clin Invest. 2013;123(7):2816-2831.

10. Skosnik PD, Edwards CR, O’Donnell BF, Steffen A, Steinmetz JE, Hetrick WP. Cannabis use disrupts eyeblink conditioning: evidence for cannabinoid modulation of cerebellar-dependent learning. Neuropsychopharmacology. 2008; 33(6):1432-1440.

11. Tonini R, et al. ERK-dependent modulation of cerebellar synaptic plasticity after chronic Delta9-tetrahydrocannabinol exposure. $J$ Neurosci. 2006;26(21):5810-5818

12. Stella N. Cannabinoid and cannabinoid-like receptors in microglia, astrocytes, and astrocytomas. Glia. 2010;58(9):1017-1030.

13. Stella N. Endocannabinoid signaling in microglial cells. Neuropharmacology. 2009;1:244-253.

14. Molina-Holgado F, et al. Endogenous interleukin-1 receptor antagonist mediates anti-inflammatory and neuroprotective actions of cannabinoids in neurons and glia. J Neurosci. 2003; 23(16):6470-6474.

15. Jones RT, Benowitz N, Bachman J. Clinical studies of cannabis tolerance and dependence. Ann NY Acad Sci. 1976;282:221-239.

16. Braitenberg V, Heck D, Sultan F. The detection and generation of sequences as a key to cerebellar function: experiments and theory. Behav Brain Sci. 1997;20(2):229-245

17. Mathew RJ, Wilson WH, Turkington TG, Coleman RE. Cerebellar activity and disturbed time sense after THC. Brain Res. 1998;797(2):183-189.

18. O'Leary DS, et al. Marijuana alters the human cerebellar clock. Neuroreport. 2003;14(8):1145-1151. 